\title{
MIGRAÇÕES INTERNACIONAIS CONTEMPORÂNEAS E PROCESSOS DE IN/EXCLUSÃO: UM ESTUDO A PARTIR DE MATÉRIAS LEGISLATIVAS
}

\author{
HOLDERBAUN, L. S. ${ }^{1}$; LÖBLER, G. N. ${ }^{2}$; PEREIRA, L.K.A. ${ }^{3}$; NEDWED, A. P.4; HILLESHEIM, B. ${ }^{5-}$.
}

PALAVRAS-CHAVE: migração, inclusão, governamento, biopolítica.

\begin{abstract}
RESUMO
As migrações internacionais, nas últimas décadas, têm se reconfigurado nos cenários global, nacional e local, resultando naquilo que se denomina crise migratória, e que marca a intensa mobilidade de sujeitos oriundos de países afetados por conflitos políticos, bélicos e catástrofes naturais para países política e socioeconomicamente mais estáveis. No Brasil, a última década compreende, sobretudo, ondas migratórias oriundas de países sulamericanos, africanos, caribenhos e médio-orientais. Diante dos crescentes deslocamentos internacionais, o artigo apresenta um recorte da pesquisa Migração e processos de in/exclusão, a qual problematiza os processos de in/exclusão e as estratégias biopolíticas de governamento da população de migrantes, tomando como materialidade de análise as matérias legislativas de três municípios gaúchos, tramitadas entre 2013 e 2017. A discussão tecida neste texto refere-se a uma parcela dos dados particulares ao município de Venâncio Aires (RS), a qual compreende as leis ordinárias e complementares, projetos de lei dos poderes Executivo e Legislativo, bem como sessões da câmara municipal, dentro do período designado. Aos documentos que possuem reconhecimento de caracteres, foram aplicados descritores direta e indiretamente relacionados ao tema de pesquisa; quanto aos demais, foi realizada a leitura dinâmica dos documentos, a fim de identificar menções à migração. Valendo-se dos operadores conceituais postulados, a análise evidencia a incipiente visibilidade dos migrantes nas esferas social, política e cultural municipais, sobretudo no campo da assistência social. Por fim, discute-se o modo como as dinâmicas de in/exclusão da população migrante são perpassadas pelos acionamentos biopolíticos vinculados à ação do Estado e à governamentalidade neoliberal.
\end{abstract}

\section{CONTEMPORARY INTERNATIONAL MIGRATIONS AND PROCESSES OF IN/EXCLUSION: A STUDY DRAWING ON LEGISLATIVE DOCUMENTS}

KEYWORDS: migration, inclusion, government, biopolitics.

\begin{abstract}
International migration, in the last decades, has been changing at the global, national and local levels, resulting in what has been called a humanitarian crisis, and which marks the intense mobility of people from countries affected by political and bellic conflicts and natural catastrophes to politically and socioeconomically more stable countries. In Brazil, the last decade encompasses, mainly, migratory waves from South American, African, Caribbean and Middle Eastern countries. In the face of growing international displacements, the article presents a segment of the research Migration and processes of in/exclusion, which problematizes the processes of in/exclusion and the biopolitical strategies for governing the migrant population, drawing on legislative documents from three municipalities in Rio Grande do Sul (Brazil), processed between 2013 and 2017. The discussion carried out in this writing refers to a section of the data particular to the city of Venâncio Aires (RS, Brazil), which comprises ordinary and complementary laws, bills from the Executive and Legislative branches, as well as council meetings, within the designated time frame. Keywords directly and indirectly related to the research topic were applied to the documents that allow for character recognition; alternatively, the remaining documents were scan-read in order to identify any mentions to migration. Drawing upon the alluded operating concepts, the analysis reveals the incipient visibility of migrants in the city's social, political and cultural domains, particularly in the field of social assistance. Finally, the discussion focuses on how the dynamics of in/exclusion are intertwined with the biopolitical acts embedded in the actions of the state and neoliberal governmentality.
\end{abstract}

${ }^{1}$ Graduanda do curso de Psicologia da Universidade de Santa Cruz do Sul (UNISC) e bolsista de iniciação científica (PUIC) no grupo de pesquisa Políticas Públicas, Inclusão e Produção de Sujeitos.

2 Graduanda do curso de Psicologia da Universidade de Santa Cruz do Sul (UNISC) e bolsista de iniciação científica (CNPq) no grupo de pesquisa Políticas Públicas, Inclusão e Produção de Sujeitos.

${ }_{3}$ Graduanda do curso de Psicologia da Universidade de Santa Cruz do Sul (UNISC) e bolsista de iniciação científica (Fapergs) no grupo de pesquisa Políticas Públicas, Inclusão e Produção de Sujeitos.

${ }_{4}^{4}$ Psicóloga graduada pela Universidade de Santa Cruz do Sul (UNISC). Colaboradora no grupo de pesquisa Políticas Públicas, Inclusão e Produção de Sujeitos.

${ }^{5}$ Psicóloga, doutora em Psicologia (PUCRS), professora e pesquisadora do Programa de Pós-Graduação em Educação e Mestrado Profissional em Psicologia (UNISC). Coordenadora do grupo de pesquisa Políticas Públicas, Inclusão e Produção de Sujeitos. E-mail: betinah@unisc.br 


\section{INTRODUÇÃO}

Barcos superlotados, multidões a caminhar, travessias inóspitas, construção de muros, cercas de arame farpado, grandes e infinitas barracas enfileiradas, corpos de pessoas afogadas à beira do mar... Essas são algumas das imagens - infelizmente comuns - que estampam manchetes e noticiários cada vez que a mídia captura a migração e o refúgio como pauta. Essas cenas, de acordo com Milesi e Coury (2017), denunciam uma característica de nossa época: a mobilidade humana sem precedentes. Nesse sentido, o deslocamento forçado tem atingido números recordes, conquistando visibilidade e espaço crescentes nos debates e agendas públicas.

Na metade de 2020, os migrantes internacionais totalizaram 280,6 milhões de pessoas (MIGRATION DATA PORTAL, 2021). Diante da complexidade da questão e dos desafios colocados por esse fluxo intenso, muitas vezes o debate é permeado por posturas xenófobas e pela politização da questão, sendo fundamental buscar que "a discussão seja marcada pelo reconhecimento do direito de migrar, dos direitos e necessidade de proteção das pessoas em situação de mobilidade e das contribuições que os migrantes e refugiados trazem - tanto para os Estados de acolhida, como para os de origem" (MILESI; COURY, 2017, p. 9).

Os movimentos migratórios são, portanto, um fenômeno global. Bauman (2017), entretanto, adverte que, apesar de já vivermos em um mundo cosmopolita, a migração é um problema que necessita ser administrado em nível local. Assim, o presente artigo discute como os processos migratórios são gerenciados nos municípios, debruçando-se sobre as discussões legislativas de Venâncio Aires, um município de pequeno porte do interior do Rio Grande do Sul. Para tanto, o artigo organiza-se da seguinte forma: em um primeiro momento, realiza-se uma contextualização da migração internacional contemporânea e o contexto de Venâncio Aires como uma cidade de acolhida de alguns grupos migrantes; após, são descritos os procedimentos investigativos e os operadores teóricos-metodológicos que embasaram o estudo; a seguir, discute-se, a partir dos documentos analisados, como a visibilidade desses grupos no contexto local busca incluí-los no sentido de melhor governar estes corpos e, ao mesmo tempo, como tal visibilidade permite que se estabeleça um enlace ético e solidário a partir do reconhecimento de outros corpos.

\section{FLUXOS MIGRATÓRIOS CONTEMPORÂNEOS E O MUNICÍPIO DE VENÂNCIO AIRES}

Tomando como ponto de partida o cenário global referente à migração, encontram-se dados divulgados em 2010 no relatório da Organização Internacional para as Migrações (OIM, 2019), apontando que, em números absolutos, existiam 220,78 milhões de pessoas migrantes. Em relatório publicado em 2019, pelo Observatório das Migrações Internacionais (OBMigra), é possível visualizar a ocorrência de um crescimento de $23 \%$ dos deslocamentos mundiais, uma vez que, nesse ano, os números apontavam para a existência de 272 milhões de migrantes espalhados pelo mundo, correspondendo, assim, a 3,5\% da população mundial (CAVALCANTI; OLIVEIRA; MACÊDO; PEREDA, 2019). Em 2020, esse percentual cresceu para 3,6\%, totalizando 280,6 milhões de deslocados internacionais. No relatório de 2019 da OBMigra (CAVALCANTI; OLIVEIRA; MACÊDO; PEREDA, 2019), obtêm-se informações sobre os deslocamentos forçados, que batem recordes: 41 milhões de pessoas se encontram nessa situação, desconsiderando-se o número de refugiados, que chegam a aproximadamente 26 
milhões. Analisando tais documentos, torna-se válido apontar que a Convenção de 1951 relativa ao Estatuto dos Refugiados, realizada em Genebra e que trata sobre a proteção internacional dos refugiados, define que o termo refugiado deve ser aplicado para qualquer pessoa que, por razões relacionadas a raça, grupo social, opiniões políticas ou religião, se encontre fora do país de nacionalidade por temer ser perseguida. Em virtude de tais acontecimentos, esses sujeitos têm sua segurança ameaçada no país de residência habitual, e, por essa razão, pedem proteção e asilo em outro país considerado seguro. A comunidade internacional passou a atentar-se aos refugiados a partir da Primeira Guerra Mundial. É importante ressaltar que a Convenção de 1951 cria uma limitação temporal, compreendendo que, para que um indivíduo fosse considerado refugiado, o seu deslocamento deveria ter ocorrido antes de $1^{\circ}$ de janeiro de 1951 . Apenas 16 anos mais tarde, a partir do Protocolo de 1967, é revogada a parcela que se refere à restrição temporal (ACNUR, 1951 [2021]).

Conforme o ACNUR (Alto Comissariado das Nações Unidas para os Refugiados) (2016), o refugiado difere do migrante, já que a migração implica um processo voluntário na busca por melhores condições econômicas, podendo optar por retornar ao seu país de origem e continuar recebendo a proteção do seu governo. Em contrapartida, os refugiados não podem retornar às suas casas com segurança e não recebem proteção do seu país de origem.

Por circunstâncias diversas, mas com a mesma intensidade que os deslocamentos em busca de refúgio, ocorrem os deslocamentos forçados. 0 termo migrações forçadas, conforme definido pelo ACNUR (2020), possui caráter generalista e abrange diversos tipos de deslocamentos ou movimentos involuntários. A agência da ONU para refugiados ainda menciona que guerras e conflitos continuam sendo as principais razões para 0 deslocamento forçado. Em 2020, 1\% da população mundial se deslocou dessa maneira.

As razões para o crescimento de todos esses números de forma tão expressiva são variadas: procura por melhores condições de emprego, crises políticas nos países de origem, perseguições ideológicas, mudanças climáticas e/ou desastres naturais. Ao trazer essa temática para discussão no cenário brasileiro, observa-se que o país não ocupa uma das primeiras posições no ranking de destino dos migrantes e refugiados, haja vista que apenas 1.085.673 indivíduos da população brasileira correspondem a esse grupo devidamente registrados com base em todos os amparos legais (CAVALCANTI; OLIVEIRA; MACEDO, 2020), sendo esse número equivalente a menos de $1 \%$ do índice populacional do país. Dentro desse contingente, as nacionalidades preponderantes são as haitianas, venezuelana, paraguaia, argentina e boliviana. A implicação desse baixo número é a falta de políticas públicas e medidas governamentais que invistam nessas vidas, sendo isso exemplificado nos dados do Instituto Brasileiro de Geografia e Estatística (IBGE, 201911): somente 215 cidades no país oferecem algum tipo de serviço aos imigrantes ou refugiados registrados, os quais estão presentes em 3.876 dos 5.568 municípios brasileiros. Contudo, vale ressaltar que a situação no Brasil já foi mais débil até meados de 2016, pois a materialidade jurídica que regulamentava toda a questão migratória era a Lei $n^{\circ} 6.815$ de 1980 (Estatuto do Estrangeiro (BRASIL, 1980), elaborada no auge da ditadura militar brasileira, tendo como objetivo um migrante que não ameaçasse a segurança nacional. Em 2017, acontece o sancionamento da Lei $n^{\circ} 13.445$ (BRASIL, 2017), que possui suas bases e diretrizes fundadas nos Direitos Humanos, olhando para o recém-chegado como uma vida inteira e não apenas como um corpo que pode ou não representar ameaça ao Brasil.

1 Informações obtidas no site: https://www12.senado.leg.br/noticias/materias/2020/02/03/cdh-vai-debater-condicao-de-imigrantes-nobrasil. 
Nesse cenário ainda tímido, os estrangeiros que chegam espalham-se por todo território nacional, mas se concentram nas regiões sudeste (55,1\%), especialmente São Paulo, e sul do país $(20,5 \%)$ devido às oportunidades laborais ao final da cadeia produtiva do agronegócio (frigorífico - abates de suínos, bovinos, aves), de acordo com o mais recente relatório anual da OBMigra (CAVALCANTI; OLIVEIRA; MACEDO, 2020). Focando no estado do Rio Grande do Sul, durante o ano de 2019 obtiveram-se 6.566 registros migratórios e em 2020 esse número despenca: apenas 1.523, reduzindo em 76,8\% a quantidade de migrantes que se instalam (CAVALCANTI; OLIVEIRA; MACEDO, 2020). É nesse cenário que a pesquisa "Migração e processos de in/exclusão" discute os dados produzidos nos municípios de Lajeado, Santa Cruz do Sul e Venâncio Aires, sendo que, no presente texto, o foco se dá sobre a última cidade citada.

Venâncio Aires se caracteriza como um município de pequeno porte, localizado no centro do estado do Rio Grande do Sul. A cidade possui suas bases econômicas fundamentadas na indústria do tabaco, agronegócio, setores de metal mecânico, confecções, moveleiro e, ainda, o abate de bovinos é forte no município, dando à cidade a colocação do segundo lugar estadual na categoria ${ }^{2}$. Tais dados tornam Venâncio Aires potencialmente atrativa para a chegada de imigrantes que buscam melhor qualidade de vida. Apesar dos indicadores revelarem uma queda significativa entre 2019 e 2020 nos registros migratórios na região sul do Brasil (CAVALCANTI; OLIVEIRA; MACEDO, 2020), o município em questão segue recebendo grandes quantidades de imigrantes: média de um imigrante por dia, de acordo com dados de janeiro de 2021 (HENCKES, 2021).

Ressalta-se que a atuação de Venâncio Aires no acolhimento aos migrantes é notável há mais de uma década. Em 2019, estimava-se que, nos últimos dez anos, o município havia acolhido cerca de 50 refugiados (KIST, 2019), número expressivo considerando-se o tamanho da sua população de aproximadamente 71.973 habitantes (IBGE, 2020). Da mesma forma, dados fornecidos ao grupo de pesquisa pela Polícia Federal revelam que a cidade se destacou como aquela que, no Vale do Rio Pardo, concedeu o maior número de vistos humanitários no ano de 2018, os quais foram designados a 51 imigrantes haitianos. Em 2011, o município foi reconhecido por suas ações de acolhida aos refugiados, tendo recebido o título de Cidade Solidária pelo ACNUR (Alto Comissariado das Nações Unidas para os Refugiados) (MULLER, 2013). Atualmente, há o registro de 250 imigrantes lotados em Venâncio Aires, os quais recebem assistência através do programa "Setor de Imigrante", coordenado pela Secretaria Municipal de Habitação e Desenvolvimento Social. O programa existe há um ano e, atualmente, acompanha imigrantes de cinco países: Venezuela, Haiti, Argentina, Colômbia e El Salvador (HENCKES, 2021). Entre os fluxos migratórios atuais, o mais expressivo no município é o venezuelano. Em janeiro de 2020, Venâncio Aires contou com a chegada em massa de imigrantes venezuelanos ao município, totalizando 54 pessoas, as quais foram interiorizadas pela Operação Acolhida, após terem cruzado a fronteira entre a Venezuela e o Brasil e se instalado em Roraima (COORDENADORIA, 2020). A pesquisa de Holderbaun (2020) constatou, por meio de entrevista realizada com uma assistente social do município, que se observa a chegada de grupos de venezuelanos desde 2019, com uma intensificação ao longo de 2020, de modo que parte desses migrantes são interiorizados pelo referido programa do governo federal, ao passo que os demais chegam ao município com seus próprios recursos.

2 Informações obtidas do site https://www.venancioaires.rs.gov.br/municipio/002-aspectos-economicos. 
Assim, valendo-se dos operadores conceituais biopolítica, governamentalidade e in/exclusão, o presente artigo pretende discutir os dados produzidos a partir dos percursos metodológicos trilhados pela pesquisa "Migração e processos de in/exclusão". No decorrer desta escrita, serão expostos e discutidos os resultados apontados por um dos recortes de tal pesquisa, que investiga as estratégias biopolíticas de governamento da população migrante na cidade de Venâncio Aires durante o período de 2013 a 2017.

\section{PROCEDIMENTOS INVESTIGATIVOS}

A materialidade de pesquisa adotada na investigação consiste em matérias legislativas do município de Venâncio Aires, compreendidas entre os anos de 2013 e 2017. Nomeadamente, os documentos analisados até o momento se dividem entre as pautas e/ou atas das sessões da câmara municipal, as leis ordinárias e complementares, bem como os projetos de lei do Poder Executivo e do Poder Legislativo.

Os documentos são acessados através do site da Câmara Municipal de Vereadores de Venâncio Aires. Ressalta-se que a disponibilidade desses documentos é parcial, de modo que estão ausentes as pautas e atas das sessões da câmara realizadas nos anos de 2013, 2014 e 2016 (este último ano possui aba de acesso no site; estão faltantes, todavia, os documentos correspondentes). Os registros das sessões de 2015 e 2017 , por outro lado, estão disponíveis com algumas irregularidades. Da mesma forma, os projetos de lei do Poder Executivo e do Legislativo dos anos de 2013 e 2014 estão indisponíveis no site. Sendo assim, considera-se esta lacuna na análise de dados. 0 acesso às leis ordinárias e complementares, diferentemente dos documentos já destacados, compreende todo o período elencado para a produção de dados, com raras irregularidades.

Compõem o material os registros de 110 sessões da câmara (2015 e 2017), 323 projetos de lei do Poder Executivo (2015, 2016 e 2017), 128 projetos de lei do Poder Legislativo (2015, 2016 e 2016), 860 leis ordinárias e 69 leis complementares. Estes documentos se dividem em duas categorias: aqueles que possuem reconhecimento de caracteres e os que não possuem. Durante a sistematização dos dados, foi aplicada ao primeiro grupo a busca de descritores relacionados com 0 tema de pesquisa, nomeadamente: (i)migr(ação/ante/ões/antes), refugi(o/iado/iados), reassent(amento/ado/s), estrangeiro(s), ACNUR, Mais Médicos, (comércio/comerciante/vendedor/es) ambulante(s)/de rua, nacionalidade, Haiti(ano/s), Colômb(ia/no/s), Venezuela(no/s), Palestin(a/o/s), Cuba(no/s), Senegal(ês/eses). Para o segundo grupo de documentos, foi realizada a leitura dinâmica dos textos, a fim de verificar possíveis menções à temática de pesquisa. A escolha dos descritores que não consistem nas nomeações de diferentes tipos de migrantes/migração se deu de acordo com as nacionalidades mais presentes na região, organizações e programas associados aos migrantes, bem como atividades laborais frequentemente associadas a este segmento no cenário local.

Posteriormente, os documentos foram classificados entre aqueles que contemplam o tema de pesquisa, os que não o contemplam, além de terem sido registrados sob o título "rever" os atos legislativos que estão indisponíveis no site, bem como aqueles que apresentem potencial relação indireta com o tema de pesquisa, a fim de que possam compor a análise em caso de outras discussões corroborarem a ligação entre os temas. A seguir, apresentam-se três tabelas com as categorizações dos documentos encontrados, referentes às sessões 
da câmara, às leis ordinárias e complementares e aos projetos de lei dos poderes Executivo e Legislativo, respectivamente.

Tabela 1: Sessões da câmara de vereadores

\begin{tabular}{|c|c|c|c|c|c|}
\hline ANO & 2013 & 2014 & 2015 & 2016 & 2017 \\
\hline $\begin{array}{l}\text { CONTEMPLAM } 0 \\
\text { TEMA DE PESQUISA }\end{array}$ & \multirow{5}{*}{$\begin{array}{l}\text { Indisponíveis } \\
\text { no site da } \\
\text { Câmara. }\end{array}$} & \multirow{5}{*}{$\begin{array}{l}\text { Indisponíveis } \\
\text { no site da } \\
\text { Câmara. }\end{array}$} & 0 & \multirow{5}{*}{$\begin{array}{c}\text { Aba } \\
\text { disponível } \\
\text { no site, } \\
\text { porém } \\
\text { sem } \\
\text { acesso às } \\
\text { atas e } \\
\text { pautas. }\end{array}$} & 3 \\
\hline REVER & & & 9 & & 06 \\
\hline $\begin{array}{c}\text { NÃO SE APLICA } \\
\text { (atas e pautas } \\
\text { simultaneamente } \\
\text { indisponíveis) }\end{array}$ & & & 19 & & 06 \\
\hline NÃO & & & 24 & & 43 \\
\hline TOTAL & & & 52 & & 58 \\
\hline
\end{tabular}

Tabela 2: Leis ordinárias e complementares

\begin{tabular}{|c|c|c|c|c|c|}
\hline ANO & 2013 & 2014 & 2015 & 2016 & 2017 \\
\hline $\begin{array}{c}\text { CONTEMPLAM O } \\
\text { TEMA DE PESQUISA }\end{array}$ & 01 & 0 & 0 & 0 & 01 \\
\hline REVER & 02 & 04 & 0 & 0 & 13 (05 indisponíveis) \\
\hline NÃO & 242 & 191 & 206 & 100 & 169 \\
\hline TOTAL & 245 & 195 & 206 & 100 & 183 \\
\hline
\end{tabular}

Tabela 3: Projetos de lei dos poderes Executivo e Legislativo

\begin{tabular}{|c|c|c|c|c|c|}
\hline ANO & 2013 & 2014 & 2015 & 2016 & 2017 \\
\hline $\begin{array}{c}\text { CONTEMPLAM O } \\
\text { TEMA DE PESQUISA }\end{array}$ & \multirow{4}{*}{$\begin{array}{l}\text { Indisponiveis } \\
\text { no site da } \\
\text { Câmara. }\end{array}$} & \multirow{4}{*}{$\begin{array}{l}\text { Indisponíveis } \\
\text { no site da } \\
\text { Câmara. }\end{array}$} & 0 & 0 & 2 \\
\hline REVER & & & 1 & 0 & 0 \\
\hline NÃO & & & 179 & 86 & 186 \\
\hline TOTAL & & & 180 & 86 & 188 \\
\hline
\end{tabular}

\section{RESULTADOS E DISCUSSÃO}

Do total de 1490 documentos sistematizados na produção de dados, 7 deles referenciam diretamente o tema de pesquisa. Dentre eles, identificaram-se três sessões da câmara, de 2017, que fazem menção à migração em seus registros, as quais se referem a dois documentos encontrados na categoria de projetos de lei do Poder Executivo. A seguir, listam-se ambos os documentos, além daqueles foram encontrados somente nas abas de leis e projetos de lei, sem que fossem mencionados nas pautas e/ou atas das sessões disponíveis:

1) A Lei $n^{\circ} 5405 / 2013$, que "institui o dia 30 de março como o Dia Municipal da Comunidade Palestina e dá outras providências" (VENÂNCIO AIRES, 2013, p. 1);

2) $O$ Projeto de Lei do Executivo $n^{\circ} 0123 / 2017$, que “institui o Plano Municipal de Assistência Social 20182021" (VENÂNCIO AIRES, 2017, p. 1); 
3) 0 Projeto de Lei do Executivo $n^{\circ}$ 040/2017, que "regulamenta o pagamento de despesas de moradia e alimentação aos médicos participantes do “Programa Mais Médicos Para o Brasil'”3 (VENÂNCIO AIRES, 2017; VENÂNCIO AIRES, 2017, p. 3);

4) A Lei $n^{\circ} 5955 / 2017$, decorrente do projeto supracitado, que regulamenta o pagamento de despesas de moradia e alimentação aos médicos participantes do Programa Mais Médicos para o Brasil (VENÂNCIO AIRES, 2017. p. 1).

Os documentos 2 e 3 são discutidos, respectivamente, na sessão ordinária $n^{\circ}$ 055, de 2017 e nas sessões ordinárias $n^{\circ} 25$ e 26, do mesmo ano. A indisponibilidade de uma parcela significativa das atas e pautas das sessões da câmara impossibilitaram que se identificasse em quais delas foram postos em discussão os demais documentos. Destaca-se, ainda, que, para muitas das sessões, os únicos registros disponíveis são as pautas, as quais apresentam apenas um resumo do conteúdo de cada sessão. Desse modo, acentuam-se os obstáculos à produção de dados.

Outros documentos, além daqueles supracitados, aludem a questões potencialmente vinculadas à migração, tais como o comércio ambulante, uma vez que tal atividade profissional é frequentemente associada, na região, a determinados grupos de migrantes. A relação entre esses temas, todavia, não é explicitamente afirmada em nenhum dos documentos, mas, sim, é registrada unicamente com o intuito de problematizá-la caso se evidencie nas discussões municipais. Dentre essas ocorrências, destacam-se os exemplos da lei $n^{\circ}$ 5.614/2014, que versa sobre a fiscalização do comércio ambulante e declara a necessidade de "repressão à atividade ambulante não autorizada" (p. 2) e do projeto de lei do Executivo ${ }^{\circ}$ 068, de 17 de junho de 2015 , que afirma, em seu parecer, "a grande necessidade de atuar fortemente na fiscalização da venda de produtos ambulantes" (p. 3).

\subsection{Processos de in/exclusão e visibilidade}

Conforme anteriormente exposto, os indicadores desse intenso fluxo migratório denunciam que a temática tem adquirido cada vez mais relevância. A fim de discutir os efeitos da imigração recente, sobretudo em nível local, parte-se da perspectiva foucaultiana de governamentalidade. Em Segurança, Território e População, Michel Foucault (2008) destaca tal conceito enquanto uma modalidade de poder direcionada pelos saberes da economia política e amparada por dispositivos de segurança. Nesse sentido, não é possível pensar a governamentalidade como um poder cujo exercício se dá sobre o Estado; pelo contrário, ele opera sobre "as pessoas, os indivíduos, os homens e as coletividades" (FOUCAULT, 2008, p. 164).

Ao discutir as políticas de inclusão e governamentalidade, Maura Corcini Lopes (2009) caracteriza o neoliberalismo enquanto um conjunto de práticas que dita as "formas de vida do presente" (p. 155), direcionadas de acordo com as regras do mercado. Assim, o Estado encontra-se cada vez mais vinculado às questões econômicas, principalmente na qualidade daquele que investe em políticas sociais, ao mesmo tempo em que

\footnotetext{
${ }^{3}$ Projeto citado nas sessões ordinárias $n^{\circ} 25$ e 26 de 2017. 0 documento não consta no site da câmara e, portanto, estão indicadas na lista de referências apenas as sessões da câmara em que foi discutido o projeto.
} 
incita o investimento e o empresariamento de si. Para tanto, é necessário provocar nos sujeitos o desejo de permanecer no jogo neoliberal.

No decorrer de sua exposição, Lopes (2009) pontua que a condução de condutas próprias à governamentalidade neoliberal depende da inclusão de todos no jogo que perpetua tal racionalidade. Para que se efetive, é necessário que todos estejam capturados pelo aparelho Estatal e visíveis nas estatísticas que subsidiam as políticas públicas, as quais operam no sentido de prover aos sujeitos as condições para participar do jogo. Assim, entende-se que somente o visível é capturável. Esta é a premissa que ocupa o cerne das ações de inclusão, conforme discorre a autora. Incluir, portanto, implica tornar visível o invisível, isto é, fazê-lo existir dentro do corpo estatístico que permite a construção de uma população, a qual, por sua vez, torna-se alvo das ações do Estado. Mesmo que os sujeitos ocupem diferentes posições, não se admite que alguém perca tudo ou fique sem jogar" (LOPES, 2009, p. 155). Desse modo, a inclusão é compreendida enquanto um imperativo neoliberal, uma vez que é ela que garante a manutenção de todos em uma complexa rede que compõe a lógica de mercado.

A condução das condutas humanas possibilita aos sujeitos governarem a si mesmos dentro do jogo neoliberal, e se sustenta nos mecanismos biopolíticos empregados em sua manutenção, os quais estão intimamente ligados à ação do Estado e ao campo das políticas públicas. Nesse sentido, Lopes (2009) entende que o Estado encontra-se em expansão, fazendo-se "cada vez mais onipresente, articulado às relações de mercado, sendo investidor em políticas que frisam a importância do empresariamento de si, incentivador de políticas sociais de assistência, educacionais e inclusivas e mais voltado para o Homo oeconomicus" (LOPES, 2009, p. 155).

A inclusão é tomada enquanto invenção de nosso tempo. Tal invento, em conformidade com Lopes (2011), refere-se tanto a uma "condição de vida em luta" (LOPES, 2011, p. 07) pela garantia de direitos, ou a uma série de ações que pretendem disciplinar, controlar e vigiar determinadas populações - por exemplo, os imigrantes. Na medida em que são produzidas, as práticas inclusivas não são, portanto, naturais; mas adquirem tom imperativo no presente na medida em que diferentes dispositivos as incitam e nos produzem enquanto sujeitos.

Faz-se necessário destacar que as noções de inclusão e exclusão não são antônimas, mas andam de mãos dadas, posto que coabitam os mesmos espaços e só agem uma em relação à outra. A partir da in/exclusão desnuda-se, então, um paradoxo que, de acordo com Veiga-Neto e Lopes (2007), acaba por potencializar os parâmetros que regem a normalidade e a anormalidade. Assim, quando a diferença e a diversidade são sobrepostas parece haver um apagamento da primeira, o que reforça, dentro de um espaço supostamente inclusivo, a própria exclusão que se pretende mitigar.

Aqui, ressalta-se especificamente o papel da assistência social nas ações de inclusão, em razão de ser esse o campo em que a população migrante aparece contemplada de maneira explícita nos dados analisados, tal como visto no Projeto de Lei do Executivo $n^{\circ}$ 0123/2017, que institui o Plano Municipal de Assistência Social 2018-2021. Ao equiparar os migrantes a demais grupos frequentemente expostos a condições de vulnerabilidade, tais como a população de rua e a LGBTQIA+, o plano estabelece como ação "desenvolver diagnóstico municipal procurando, evidenciar a presença ou não de migrantes estrangeiros residentes ou de passagem no município com o objetivo de readequar as ações das políticas sociais para este segmento" (VENÂNCIO AIRES, 2017, p. 42). Assim, os migrantes adentram a zona de inclusão, mediante sua captura pelas ações estatais. 
Conforme pontuam Serpa, Virgínia e Cavalvante (2015), as políticas de assistência social se configuram como estratégias de "produção de autonomia" (p. 430), em consonância com a implicação ética e política de se capturar os sujeitos na alçada das políticas públicas: transformá-los em sujeitos de direito, deslocando-os da posição de sujeitos de caridade. Nesse sentido, pensa-se que o abrangimento da população migrante no planejamento socioassistencial municipal representa um movimento de inclusão desses sujeitos no campo dos direitos sociais. As autoras colocam, ainda, que o estatuto de sujeito de direito "assegura não somente que o indivíduo seja assistido em suas necessidades básicas, mas também na instauração das condições para o exercício da cidadania pela conquista da autonomia" (p. 430). Assim, considera-se que incluir nomeadamente os migrantes nas ações de assistência social abre espaço para que operem, progressivamente, no campo da cidadania.

No seguimento da argumentação, as mesmas autoras pontuam que a Política Nacional de Assistência Social (PNAS) se configura como um dispositivo de autonomia. Nesse sentido, ressaltam que as condições de vulnerabilidade dos beneficiários da Proteção Social Básica - junto com a Proteção Social Especial, um dos níveis de proteção atribuídos à Política Nacional de Assistência Social - devem ser mitigadas "não somente pela provisão, mas também pelo desenvolvimento das condições de autonomia" (p. 432).

Esta dimensão de autonomia, investida pela PNAS, articula-se intimamente com a concepção de inclusão discutida por Lopes (2009), a qual pressupõe a ação de tornar capturável pelo Estado o maior contingente possível de sujeitos. Uma vez visíveis e capturados pelas políticas de inclusão, aqueles sujeitos previamente excluídos das estatísticas tornam-se aptos a adentrarem e movimentarem a racionalidade neoliberal. 0 sujeito de direito, cuja autonomia é investida pelas políticas de assistência social e pelos movimentos de inclusão, governa a si mesmo no interior dessa racionalidade, de modo que seu próprio estatuto de sujeito esteja por ela constituído. Os mecanismos e as tecnologias de governamento acionados na captura de sujeitos previamente excluídos, ao contemplarem-nos nas estatísticas, sucedem, portanto, em torná-los governáveis e, assim, orientar suas ações na direção do funcionamento da sociedade de mercado.

Nesse sentido, contabilizar os migrantes no contingente populacional e torná-los visíveis assegura que esses sujeitos passem a ser produzidos pela mesma racionalidade. A passagem gradativa da condição de sujeitos de caridade para a de sujeitos de direito, isto é, a sua inclusão, está a serviço não somente da garantia de direitos, como também da manutenção da governamentalidade neoliberal no contexto do município de Venâncio Aires.

Além disso, é preciso destacar uma lacuna nos dados produzidos no recorte da pesquisa, dado que uma grande parte das matérias legislativas não estão disponíveis no site da Câmara de Vereadores municipal. Na tentativa de trazer luz ao processo migratório recente da cidade, uma entrevista com uma vereadora venâncioairense foi realizada em agosto de 2019. Na ocasião, ela ressaltou que as discussões que tangem o tema não passam pelo Poder Legislativo municipal, embora a cidade seja reconhecida como Cidade Solidária pelo Governo Federal e pelo ACNUR. A concessão desse título confere vantagens ao município, bem como aos imigrantes que acolhe. Como exemplo, a vereadora citou o extinto Programa Social de Habitação, Minha Casa, Minha Vida, em que Venâncio Aires tinha preferência ao benefício do financiamento de moradia justamente por ser reconhecida enquanto Cidade Solidária. Além disso, a vereadora explicou que a maior parte dos migrantes insere-se no mercado informal de trabalho. 
Retomando um ponto discutido anteriormente, na direção daquilo que Bauman (2017) compreende como uma convocação à ação local direcionada às problemáticas globais, a qual marca as dinâmicas contemporâneas das cidades, evoca-se o senso ético de interdependência, discutido pela filósofa estadunidense Judith Butler (2018). Ao tratar das implicações éticas envolvidas nas dinâmicas de proximidade e distanciamento, a autora argumenta que o reconhecimento da precariedade (a condição de estar exposto e passível de sofrer violência, em cenários de indução de vulnerabilidade) de vidas outras é que permite-nos incorporar um senso ético de vinculação e responsabilidade direcionado a elas. Assim, é possível que tal disposição esteja restrita "àqueles cujos rostos podemos ver, cujos nomes podemos conhecer e pronunciar, aqueles que já podemos reconhecer, cujas formas e cujo rosto são familiares" (BUTLER, 2018, p. 112). Não é isso, entretanto, que ocorre "quando uma parte do globo, moralmente ultrajada, se insurge contra as ações e os eventos que acontecem em outra parte do globo, uma forma de indignação moral que não depende do compartilhamento de uma língua ou de uma vida em comum baseada na proximidade física" (p. 112).

Butler (2018) segue afirmando que, nesses casos, algo que nos move a um enlace ético e solidário com outras vidas, e que se manifesta como imposição externa aos nossos afetos, é a imagem de sofrimento apresentada daqueles que estão distantes e cujos rostos não reconhecemos. Assim, um modo através do qual tal convocação se impõe são as "imagens e descrições do sofrimento na guerra", que "são uma forma particular de solicitação ética, que nos leva a negociar questões de proximidade e distância" (BUTLER, 2018, p. 113).

Cabe, aqui, considerar como as relações éticas nas comunidades são movidas quando aqueles que um dia estiveram distantes passam a ocupar as mesmas parcelas de espaço que os seus residentes locais. Diferentemente daquilo que ocorre com as imagens veiculadas dos conflitos bélicos e do sofrimento que impõem, a presença de imigrantes em determinado território não pode ser ignorada senão pela marginalização e invisibilidade, o que sinalizaria, se adotarmos as concepções de Butler (2018), a ausência de implicação ética e de ligação com essas vidas. Assim, não somente a política local é convocada concretamente para agir sobre demandas globais como os fluxos migratórios (BAUMAN, 2017), como também o reconhecimento da problemática parece requerer sua visibilidade, ainda que possivelmente incipiente e/ou parcial.

Ao considerarem-se os movimentos de visibilização da população migrante no município de Venâncio Aires, através das ações de diagnóstico e mapeamento desse segmento, empreendido pelo aparelho socioassistencial, compreende-se que estes possibilitam que as relações éticas comunitárias se rearranjem para abranger essas vidas e reconhecer sua precariedade. A passagem da condição de sujeitos de caridade para a de sujeitos de direito, investida pelas políticas de assistência social no município, parece depender desse reconhecimento. Todavia, é importante ressaltar que tal processo é incipiente no local, haja vista que contingentes significativos de migrantes têm sido acolhidos no município há mais de uma década (KIST, 2019), o que marca uma lacuna de pelo menos nove anos entre o recebimento de fluxos migratórios consideráveis e o planejamento municipal relativo ao mapeamento desses grupos.

Dentre os efeitos disso, destaca-se o fato de que muitos migrantes que residem ou residiram no município não estão contabilizados nos registros populacionais venâncio-airenses, conforme relatado por uma assistente social que atua no mapeamento dos migrantes em Venâncio Aires (HOLDERBAUN, 2020). Assim, ainda que os veículos midiáticos locais tenham noticiado a presença de migrantes haitianos, senegaleses, colombianos, palestinos, entre outras nacionalidades, ao longo da última década, a maioria desses sujeitos não se tornou visível 
nas estatísticas municipais, de modo que, em setembro de 2020, os registros de migrantes que residiam no município compreendiam, majoritariamente, os grupos de venezuelanos que se instalaram na cidade entre 2019 e 2020.

\section{CONCLUSÃO}

Embora muitos documentos que compõem a materialidade da pesquisa estejam indisponíveis no site da Câmara Municipal de Vereadores de Venâncio Aires, ou, ainda, incompletos, os achados apontam para a relevância da Assistência Social no que diz respeito à inclusão da população migrante em Venâncio Aires. A Constituição Federal de 1988, conforme o artigo 203, coloca que a Assistência Social é um direito universal, na medida em que "será prestada a quem dela necessitar, independentemente de contribuição à seguridade social" (BRASIL, 1988). Assim, a inclusão aqui se desloca em direção àquilo que Maura Corcini Lopes (2009) comenta a respeito das políticas de assistência social. A autora as caracteriza enquanto um dispositivo biopolítico de seguridade às populações que o Estado pretende capturar.

Na medida em que os migrantes, via políticas de assistência a nível municipal, passam a ser incluídos nos "grupos, nos registros oficiais, no mercado de trabalho, nas cotas de bolsa-assistência, na escola, etc." (LOPES; 2009, p. 156), tornam-se cognoscíveis perante o Estado e, portanto, governáveis. Assim, se faz possível não só conduzir as peças que agora participam do jogo neoliberal, mas também controlá-las.

Retoma-se, aqui, a tarefa de tornar visível o invisível, de capturá-lo e torná-lo passível de inclusão. De algum modo, capturar e tornar visíveis os sujeitos migrantes é que torna as demandas geradas pelos deslocamentos internacionais passíveis de discussão. Da mesma forma, o reconhecimento do sofrimento, das condições de vulnerabilidade e da precarização das condições de vida da população migrante é retroalimentado por tal visibilidade. Assim, o processo de tornar visível próprio às dinâmicas de in/exclusão (LOPES, 2009) é condutor do reconhecimento dessas vidas como passíveis de serem investidas eticamente pelos laços de solidariedade das comunidades, os quais têm como mediadores o aparelho Estatal e seus acionamentos biopolíticos.

Assim, pode-se apontar para a indissociabilidade entre inclusão e exclusão, bem como os efeitos paradoxais implicados nas ações que objetivam tornar visíveis os grupos migrantes: se, por um lado, trata-se de um investimento biopolítico que responde a uma governamentalidade que pretende tornar tais sujeitos participantes do jogo neoliberal; por outro, a visibilidade possibilita o reconhecimento desse outro e a constituição de relações de acolhida e solidariedade.

\section{REFERÊNCIAS}

ACNUR - ALTO COMISSARIADO DAS NAÇÕES UNIDAS PARA OS REFUGIADOS. Convenção Relativa ao Estatuto dos Refugiados. Genebra: ACNUR, 1951 [2021]. Disponível em:

https://www.acnur.org/fileadmin/Documentos/portugues/BDL/Convencao_relativa_ao_Estatuto_dos_Refugiad os.pdf. Acesso em: 12 mar. 2021.

ACNUR - ALTO COMISSARIADO DAS NAÇÕES UNIDAS PARA OS REFUGIADOS. Refugiados e migrantes: perguntas frequentes. 2016. Disponivel em: https://www.acnur.org/portugues/2016/03/22/refugiados-emigrantes-perguntas-frequentes/. Acesso em: 11 mar. 2021. 
ACNUR - ALTO COMISSARIADO DAS NAÇÕES UNIDAS PARA OS REFUGIADOS. Relatório Global do ACNUR revela deslocamento forçado de $1 \%$ da humanidade. 2020. Disponível em:

https://www.acnur.org/portugues/2020/06/18/relatorio-global-do-acnur-revela-deslocamento-forcado-de-1-dahumanidade/. Acesso em: 11 mar. 2021.

BAUMAN, Z. Estranhos à nossa porta. 1ª ed. Rio de Janeiro: Zahar, 2017.

BRASIL. Lei $n^{\circ}$ 6.815, de 19 de agosto de 1980. Brasília, DF, 1980.

BRASIL. Lei n 13.445, de 24 de maio de 2017. Brasília, DF, 2017.

BRASIL. [Constituição (1988)]. Constituição da República Federativa do Brasil de 1988. Brasília, DF: Presidência da República, [2021]. Disponível em: http://www.planalto.gov.br/ccivil_03/constituicao/constituicao.htm. Acesso em: 20 mar. 2021.

BUTLER, J. Corpos em aliança e a política das ruas: notas para uma teoria performativa de assembleia. Rio de Janeiro: Civilização Brasileira, 2018.

CAVALCANTI, L; OLIVEIRA, T; MACÊDO, M; PEREDA, L. Resumo Executivo. Imigração e refúgio no Brasil. A inserção do imigrante, solicitante de refúgio e refugiado no mercado de trabalho formal. Observatório das Migrações Internacionais; Ministério da Justiça e Segurança Pública / Conselho Nacional de Imigração e Coordenação Geral de Imigração Laboral. Brasília, DF: OBMigra, 2019. Disponível em: https://portaldeimigracao.mj.gov.br/pt/dados/relatorios-a. Acesso em 10 mar. 2021.

CAVALCANTI, L.; OLIVEIRA, T.; MACEDO, M. Imigração e Refúgio no Brasil. Relatório Anual 2020. Série Migrações. Observatório das Migrações Internacionais; Ministério da Justiça e Segurança Pública/ Conselho Nacional de Imigração e Coordenação Geral de Imigração Laboral. Brasília, DF: OBMigra, 2020. Disponível em: https://portaldeimigracao.mj.gov.br/pt/dados/relatorios-a. Acesso em 10 mar. 2021.

COORDENADORIA de Comunicação e Marketing PMVA. Prefeitura de Venâncio Aires presta assistência a venezuelanos. Olá Jornal [online], Venâncio Aires, 31 janeiro 2020. Saúde. Disponível em:

http://olajornal.com.br/prefeitura-de-venancio-aires-presta-assistencia-venezuelanos. Acesso em: 25 mar. 2020.

FOUCAULT, Michel. Segurança, território, população: curso dado no Collège de France (1977-1978). Tradução Eduardo Brandão. São Paulo: Martins Fontes, 2008.

HOLDERBAUN, L. S. Migrações internacionais e a pandemia de COVID-19: processos de acolhimento no município de Venâncio Aires/RS. 2020. Trabalho de Conclusão de Curso (Curso de Psicologia) - Universidade de Santa Cruz do Sul, Santa Cruz do Sul, 2020. Não publicado.

HENCKES, L. B. Em janeiro, Venâncio teve média de um imigrante acolhido por dia. Município de Venâncio Aires. Venâncio Aires, 10 fev. 2021. Disponível em: https://www.venancioaires.rs.gov.br/noticias/02-2021/3205-emjaneiro-venancio-teve-media-de-um-imigrante-acolhido-por-dia. Acesso em: 23 fev. 2021.

KIST, D. Venâncio já recebeu cerca de 50 refugiados nos últimos 10 anos. Folha do Mate [online], 27 novembro 2019. Disponível em: https://folhadomate.com/venancio-aires/venancio-ja-recebeu-cerca-de-50-refugiados-nosultimos-10-anos/. Acesso em: 23 mar. 2021.

LOPES, M. C. Políticas de inclusão e governamentalidade. Educação e Realidade, v. 34, n. 2, p. 153-169, mai./ago. 2009. Disponível em: http://seer.ufrgs.br/educacaoerealidade/article/view/8297/5536. Acesso em: 15 mar. 2021.

LOPES, M. C. Prefácio: políticas de inclusão e governamentalidade. In: THOMA, A. da S.; HILLESHEIM, B. (orgs.). Políticas de inclusão: gerenciando riscos e governando as diferenças. Santa Cruz do Sul: Edunisc, 2011. p. 7307.

MIGRATION DATA PORTAL. Brazil. Key migration statistics. 2021. Disponível em: https://migrationdataportal.org. Acesso em: 02 mar. 2021. 
MILESI, R.; COURY, P. Apresentação. In: Cadernos de Debates Refúgio, Migrações e Cidadania, v. 12 , n. 12. Brasília: Instituto Migrações e Direitos Humanos, 2017. Disponível em: https://www.acnur.org/portugues/wpcontent/uploads/2018/02/Caderno-de-Debates-12_Ref\%C3\%BAgio-Migra\%C3\%A7\%C3\%B5es-e-Cidadania.pdf. Acesso em: 17 mar. 2021.

MULLER, P. R. Noções de solidariedade e responsabilidade no campo da cooperação internacional para a proteção de refugiados. Revista Interdisciplinar de Mobilidade Humana, Brasília, ano XXI, n. 40, p. 229-244, jan./jun. 2013. Disponível em: http://www.scielo.br/pdf/remhu/v21n40/14.pdf. Acesso em: 25 mar. 2021.

SERPA, V.; VIRGÍNIA, C.; CAVALCANTE, S. Assistência social pública brasileira: uma política da autonomia - um dispositivo biopolítico, Revista Subjetividades, Fortaleza, v. 15, n. 3, p. 428-437, dez. 2015. Disponível em: http://pepsic.bvsalud.org/pdf/rs/v15n3/11.pdf. Acesso em: 16 mar. 2021.

VEIGA-NETO, A; LOPES, M. C. Inclusão e governamentalidade. Educação \& Sociedade, Campinas, v. 28, n. 100, p. 947-963, out. 2007. Disponível em: http://www.scielo.br/pdf/es/v28n100/a1528100.pdf. Acesso em: 14 mar. 2021. http://dx.doi.org/10.1590/S0101-73302007000300015.

VENÂNCIO AIRES. Poder Executivo. Lei $n^{\circ}$ 5405, de 06 de novembro de 2013. Institui o dia 30 de março como o Dia Municipal da Comunidade Palestina e dá outras providências. Câmara Municipal de Vereadores de Venâncio Aires, Venâncio Aires, RS, 06 nov. 2013. Disponível em:

https://www.venancioaires.rs.leg.br/camara/proposicao/Leis-ordinarias/2013/2/0/5671. Acesso em: 03 mar. 2021.

VENÂNCIO AIRES. Lei $n^{\circ}$ 5.614, de 18 de dezembro de 2014. Cria Cargo de Provimento Efetivo no Quadro Geral de Servidores do Município. Câmara Municipal de Vereadores de Venâncio Aires, Venâncio Aires, RS, 18 dez. 2021. Disponível em: https://www.venancioaires.rs.leg.br/camara/proposicao/Leis-ordinarias/2014/1/0/434. Acesso em: 03 mar. 2021.

VENÂNCIO AIRES. Projeto de Lei do Executivo, $n^{\circ}$ 68, de 08 de julho de 2015. Autoriza Contratação Temporária por Excepcional Interesse Público. Câmara Municipal de Vereadores de Venâncio Aires, Venâncio Aires, RS. 08 jul. 2021. Disponível: https://www.venancioaires.rs.leg.br/camara/proposicao/Projetos-de-LeiExecutivo/2015/4/0/4480. Acesso em: 03 mar. 2021.

VENÂNCIO AIRES. Câmara Municipal de Vereadores de Venâncio Aires. Ata $n^{\circ}$ 25/2017. Sessão ordinária $n^{\circ} 25$, de 29 de maio de 2017. Câmara Municipal de Vereadores de Venâncio Aires, Venâncio Aires, RS, 29 mai. 2017. Disponível em: https://www.venancioaires.rs.leg.br/camara/atas/sessao_ordinaria/2017/2/0/186. Acesso: 03 mar. 2021.

VENÂNCIO AIRES. Câmara Municipal de Vereadores de Venâncio Aires. Ata $n^{\circ}$ 26/2017. Sessão ordinária ${ }^{\circ} 26$, de 05 de junho de 2017. Câmara Municipal de Vereadores de Venâncio Aires, Venâncio Aires, RS, 05 jun. 2017. Disponível em: https://www.venancioaires.rs.leg.br/camara/atas/sessao_ordinaria/2017/2/0/184. Acesso em: 03 mar. 2021.

VENÂNCIO AIRES. Poder Executivo. Lei $\mathrm{n}^{\circ}$ 5955, de 08 de junho de 2017. Regulamenta o pagamento de despesas de moradia e alimentação aos médicos participantes do "Programa Mais Médicos para o Brasil", conforme portaria interministerial MS/MEC $n^{\circ} 1.369$, de 08 de julho de 2013 e portaria MS $n^{\circ} 30$, de 12 de fevereiro de 2014. Câmara Municipal de Vereadores de Venâncio Aires, Venâncio Aires, RS, 08 jun. 2017. Disponível em: https://www.venancioaires.rs.leg.br/camara/proposicao/Leis-ordinarias/2017/5/0/5445. Acesso em: 03 mar. 2021.

VENÂNCIO AIRES. Poder Executivo. Projeto de Lei $n^{\circ}$ 123, de 19 de dezembro de 2017. Institui o Plano Municipal de Assistência Social 2018-2021. Câmara Municipal de Vereadores de Venâncio Aires, Venâncio Aires, RS, 19 dez. 2017. Disponível em: https://www.venancioaires.rs.leg.br/camara/proposicao/Projetos-deLei-Executivo/2017/1/0/4228. Acesso em: 03 mar. 2021.

OIM - ORGANIZAÇÃO INTERNACIONAL PARA AS MIGRAÇÕES. Migração e migrantes: panorama mundial. Geneva: Organização Internacional Para As Migrações, 2019. 42 f. Disponível em: https://publications.iom.int/books/world-migration-report-2020. Acesso em: 14 mar. 2021. 